\title{
ALLIANCE FOR DEEP RENOVATION IN BUILDINGS. A STEP FORWARD TO THE COMMON EUROPEAN VOLUNTARY CERTIFICATION SCHEME
}

\author{
Johann Zirngibl ${ }^{l,}$, Carolina Mateo-Cecilia, and Carlos Espigares-Correa². \\ ${ }^{1}$ CSTB (Centre Scientifique et Technique du Batiment) 84 Av. Jean Jaurès Champs-sur-Marne 77447 Marne-la-Vallée Cedex 2, France. \\ ${ }^{2}$ IVE (Instituto Valenciano de la Edificación), R+D+I Department. Av. Tres Forques 98, 46018 Valencia, Spain. \\ With the contribution of: Mathieu RIVALLAIN (CSTB, France), Corinne MANDIN (CSTB, France), Jana BENDZALOVA (ENBEE, \\ Slovakia), Robert COHEN (VERCO, UK), Saadia ANSARI (VERCO, UK), Greg WARING (VERCO, UK), Pawel WARGOCKI (DTU, \\ Denmark), Christophe GERARD (CERTIVEA, France), Yona KAMELGARN (CERTIVEA, France), Graziano SALVALAI (POLIMI, \\ Italy), Marta Maria SESANA (POLIMI, Italy).
}

\begin{abstract}
The ALDREN project (ALliance for Deep RENovation in Buildings) is the extended development and the implementation of a common European Voluntary Certification Scheme (EVCS) for non-residential buildings based on the EPBD Art. 11 (9) and CEN / ISO standards. ALDREN is a coordination and support action (CSA). It focuses on existing tools and schemes (partly developed by the European Commission), on networking, standardization, awareness raising and communications.

The main goal of ALDREN is to encourage the construction sector value chain stakeholders to undertake deep renovation projects on their properties. Issuing completed and verified Energy Performance Certificates (EPC) before and after renovation, are to contribute to the development of innovative financial valuation of building assets and financing instruments (e.g. integrating loans with differentiated interest rates) and establishing business case for deep renovation to motivate private investment.

The core objectives of the ALDREN project are:

- To provide a harmonized European energy performance rating methodology based on the European Voluntary Certification Scheme (EVCS) verified by measurements to increase comparability, confidence and market uptake by standardized solutions (CEN/ISO standards) at European scale;

- To associate low energy renovation with high quality indoor environments to trigger renovation and to promote solutions supporting health and well-being;

- To align market recognition of high quality with enhanced building value and capacity building.

The ALDREN overarching outcome will be the infrastructure to enable market transformation for deep renovation and directly support the EU policies (EED, EPBD). Specific solutions and step-by-step renovation process will be integrated in a consistent, common way in a Building Renovation Passport (BRP). The ALDREN BRP will be aligned with the GABC (Global Alliance for Building and Construction) Building Passport initiative, seconded by DG Grow and DG Environment and with the current initiatives for residential buildings.

The non-residential sector (office buildings and hotels) is to be considered as a first step. To demonstrate the ALDREN approach, the upgraded EVCS will be implemented in pilot office buildings and hotels in different climates over the European territory. However, the ALDREN approach could be adapted to other market sectors, in a further development.

ALDREN renovation protocols may be used as individual modules in existing schemes or as standalone tool, being potentially overtaken by Member States of the European Union.
\end{abstract}

\section{INTRODUCTION}

The European Commission estimates that achieving energy and climate targets will need additional investments for $€ 170$ billion[1] to decarbonise and renovate the existing building stock to the highest energy performance standard. According to DG Ener[2], buildings are responsible for approximately $40 \%$ of energy consumption and $36 \%$ of $\mathrm{CO}_{2}$ eq. emissions in the EU.

In addition, the stock of buildings in the EU is relatively old, considering that about $35 \%$ of the EU's buildings are over 50 years old. According to European Parliament figures[3], the current renovation rate of existing buildings is low, with only about $1-2 \%$ of the building stock renovated each year, and the vast majority of these renovations do not utilise the full potential energy savings that could be achieved. Euro ACE states that only around $15 \%$ of current building refurbishments incorporate any significant energy efficiency improvements[4], which definitely seems insufficient to meet the European ambitious targets.

Several studies confirm that one of the major barriers to improve building renovation numbers across Europe is the absence, in most cases, of a holistic strategy to design, finance and implement renovation protocols and

\footnotetext{
* Corresponding author: johann.zirngibl@ecstb.fr
} 
the lack of a strong relationship between the different stakeholders. There is a need to renovate the building stock with holistic tools and methods and with a common language between the stakeholders in order to achieve the EU energy and climate targets.

According to article 11 (9) of the Energy Performance of Buildings Directive, the European Voluntary Certification Scheme (EVCS) is considered a market driven vehicle to boost energy building renovations in non-residential buildings. Non-residential buildings account approximately for $25 \%$ of the floor area distribution in Europe according to an EU Survey run by BPIE in 2012 on buildings[5], and therefore are considered as drivers of this energy transition that Europe is looking for.

In this context, ALDREN intends to encourage investment and accelerate the movement towards a nearly zero energy non-residential building stock across the EU, as targeted by 2050 to meet Paris Agreement commitments. The back-bone of ALDREN is the European common Voluntary Certification Scheme (EVCS) which will be used to track the deep renovation process. ALDREN pilots will be among the first applications of the EVCS, either as an energy module in existing schemes, as standalone, or to be overtaken by the Member States.

\section{ADAPTATION OF A COMMON LANGUAGE (T2.1)}

\section{The need for an overall integration of components in the EVCS language}

Property owners, investors, developers, insurance companies, banks are rational decision makers, grounding their investments and arbitration on building assets attractivity, economic and financial valuation, and risks mitigation.

For office buildings and hotels - as for the overall building stock - deep renovation (ambitioning 60\% primary energy savings through building retrofit), or even the move to NZEB level, will not be triggered for the only sake of energy performance and related direct financial benefits over buildings lifespan.

The development of holistic procedures, assessing the overall benefits from building deep renovation regarding energy performance, confidence in the savings, high quality indoor environments, financial valuation are needed to engage property owners and stakeholders on deep renovation pathways.

The ALDREN procedure consolidates an approach to deep renovation assessment, integrating:

- A European harmonized energy performance rating, offering comparability and transparency across the EU

- An energy Performance verification protocol to enhance confidence (you got what has been promised), building value and management tools

- A health and well-being assessment framework offering the integration of indoor air quality, comfort and health in the scope of deep energy renovation,

- The financial valuation of both energy and nonenergy benefits (such as increased productivity in office buildings)

- A Building Renovation Passport (BRP) and roadmap.

ALDREN is not only the superimposition of these individual methodological pieces but also their overall integration, exploiting the interactions in between. For example, a given energy retrofit action will contribute to the improvement of the predicted energy performance (rating) but also to the assessment of refined actual energy targets, to the enhancement of thermal comfort, indoor environments, to increased well-being and productivity.

- Last, the ALDREN procedure is designed in the perspective of a European library for building components, systems and equipment description, according to the EU Eco-design directive implemented into Industry standards.

- ALDREN will deliver operational procedures to the previously mentioned topics (further details are also provided in the next sections). These articulate the individual protocols along with the deep renovation stages. The data to be collected and the proposed data structuring according to 4 levels corresponding the data process and the readiness of a building renovation passport and cover - are specified. The ALDREN procedures are designed to be adopted either as a standalone standard or as a set of individual methodological pieces that may be taken up in already existing voluntary environmental certification schemes across the EU (i.e. BREEAM, HQE, DGNB, IVE).

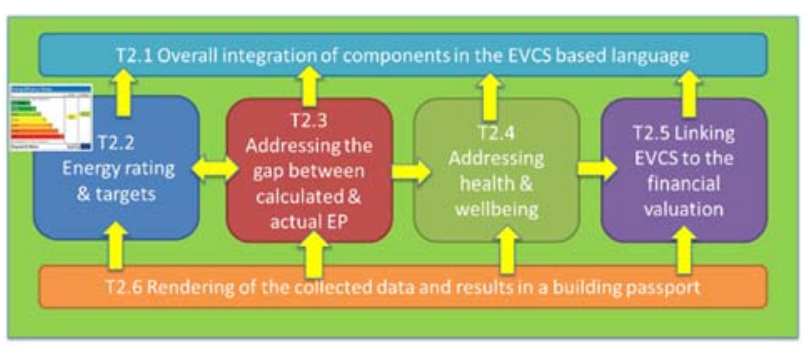

Fig. 1. ALDREN in a nutshell, 6 tasks for consolidation and adaptation of an EVCS (European Voluntary Certification Scheme) based common language

\section{ENERGY RATINGS \& TARGETS (T2.2)}

Energy ratings and targets, reported in Energy Performance Certificates (EPC), are the main accessible and transparent advisory tools for building owner, tenant, financial institutions and policy makers.

The role of energy performance certificates (EPC) has been strengthened in the Directive 2018/844 amending EPBD. The Directive 2018/844 recommends comparing energy performance certificates issued before and after the renovation. The Member States are asked to ensure 
that the national certificates are of good quality to provide reliable information.

However, to manage large buildings stocks at European scale, the national EPCs do not provide yet direct comparability of energy performance ratings across the EU and do not consider in the same way the innovative solutions and all technical systems[6] .

EU targets of decarbonization, energy efficiency and primary energy savings, are of a societal and environmental importance, while the interest of private building owner is often determined by costs. Both, societal and building owner aspects, are brought together in ALDREN Voluntary Common European Union Certificate (EVC)[7] .

ALDREN EVC sets the conditions for a consistent benchmark of energy performance at EU level, based on an EU comparable scale with one reference point reflecting approximately the cost optimal level of energy performance in 2013 as today only transparent and comparable value.

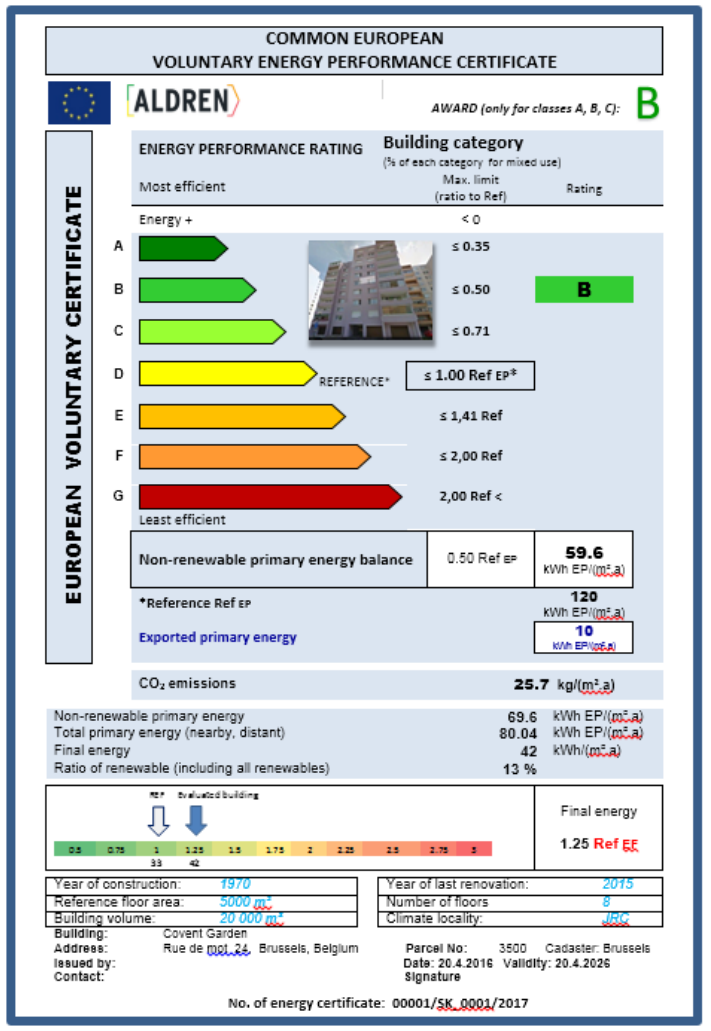

Fig. 2. ALDREN Energy Performance Certificate template.

The energy performance indicators ensure transparency and reliability through:

- A harmonized and transparent assessment methodology based on new CEN standards developed under Commission Mandate M/480, using hourly calculation step, local climate conditions, national use patterns and European primary energy factors

- An energy class of the current state of the building and an assumed energy class after realization of recommended improvements and where potential savings are reported with a potential link to an optional building renovation passport (recommended by EPBD amendment),

\section{ALDREN EVC provides also}

- A possible link with financial institutions to facilitate energy efficiency renovations, e.g. by the reduction of the risk of investment for private sector,

- A link with asset valuation and financial strategies, possible link with existing voluntary certification schemes (IVE, HQE, BREEAM, DGNB),

- Additional numerical indicators, for the entire building's overall energy use (recommended by EPBD amendment)

- Integration of energy performance indicators and related data documented in the Building Renovation Passport.

The options for the scale, benchmark reference, primary energy factors, occupancy and climate were tested on several model buildings before final proposal for EVC energy rating.

The packaged solutions for renovation were tested against proposed energy classes considering the appropriate sequence and avoiding the lock-in effect.
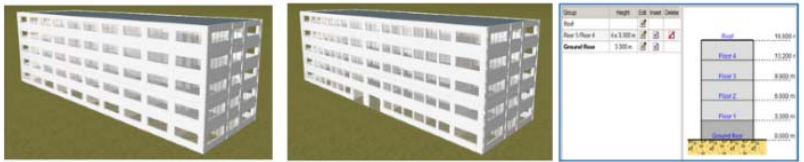

Fig. 3. Energy rating procedure testing model.

\section{ADDRESSING THE GAP BETWEEN CALCULATED AND ACTUAL EPC (T2.3)}

The energy performance gap commonly observed in Europe between the predictions of models used for asset ratings, and measurements of buildings in use has two main causes[8] .

- Firstly, simplified asset rating models are consistently unable to predict accurately the actual in-use energy consumption of nonresidential buildings, especially those with airconditioning systems.

- Secondly, inefficient and/or poorly implemented control strategies are common and persist in-use due to management aiming to avoid complaints rather than also achieve efficient operation.

To overcome these two issues, ALDREN proposes:

- Following the best practice (e.g. Australia), that more advanced models are used, in which the building and its HVAC system and controls are modelled simultaneously and in detail[9]. 
- That an accurate description of operations is developed from the simulation model, implemented regarding the capabilities of the intended users and / or operators of the building and verified as working correctly by intensive commissioning and fine tuning during early operation.

- That a base building operational energy performance target is set for the renovation, corroborated at the design stage by the advanced modelling, then verified during the first year of operation through a properly specified energy sub-metering system.

It is essential that when comparisons of modelled and measured energy use are made, it is on a like-for-like basis, meaning that comparable boundary conditions are applied in the model to those experienced in the real building (see Figure 4). For example, this includes ensuring that the hours of use in different zones of the building, and the weather occurring during the year of measurement for the real building, are replicated in the model. Knowledge of the actual energy use of the prerenovated building can support identification of appropriate renovation measures. Granular sub-metering will help identify and close any performance gaps between the predicted and measured energy consumption of the building after renovation and can underpin a verified rating.

To deliver these goals, ALDREN will produce two key documents:

- A design for testability protocol, which will be applied during each of the critical stages of renovation to ensure that the performance outcome achieves the design intent.

- A performance verification tool, which facilitates the calculation of the performance gap before and after renovation, providing insight into any deviation from design intent.

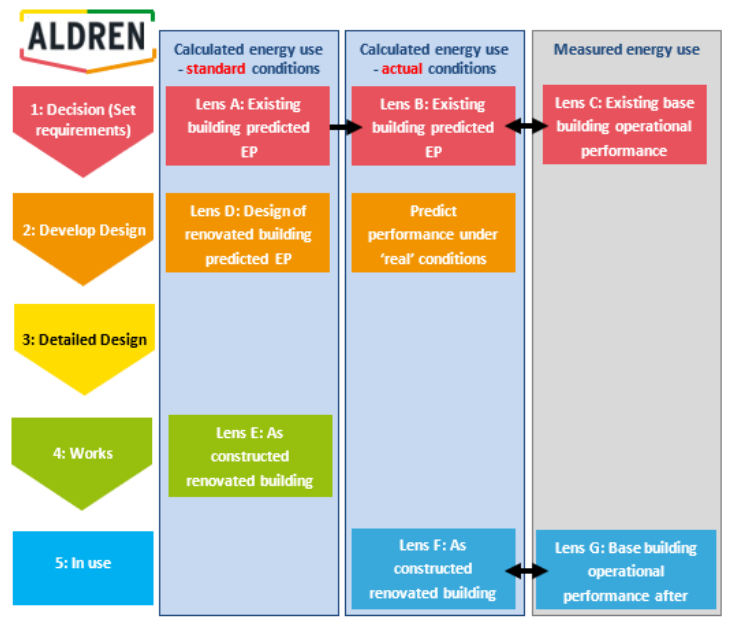

Fig. 4. Calculations and measurements recommended by the ALDREN design for testability protocol at each of the five ALDREN phases for a deep renovation project
The fundamental outcome of the ALDREN approach is that through following the design for testability protocol, and therefore ensuring that energy performance is considered by all parties at each key stage of the renovation process, the in-use energy performance of the renovated building will be as intended. An important element of the protocol is to include predictions of the building energy performance under actual conditions, as well as under standard conditions, at both the pre- and post-renovation stages.

In order to verify the calculated EVCS energy rating of a renovated building under standard conditions of use, the performance verification tool presents a side-by-side comparison of energy consumption predictions and measurements under actual conditions of use, quantifies the magnitude of the variances and assesses their acceptability.

\section{HEALTH \& WELLBEING (T2.4)}

According to the World Green Building Council[10] and other reports[11, 12, 13], the dominant cost of running commercial buildings, in the so-called "developed countries", is associated with the occupants. These costs are estimated to constitute up to $90 \%$ of all building operation costs. The remaining costs are rental at $9 \%$ and energy, which is making up only $1 \%$ of the total costs. Research has shown that the indoor environment quality (IEQ), in particular thermal, and acoustic environment, light, indoor air quality and the ability of occupants to control these, is an important determinant of the work efficiency[13, 14]. IEQ has also been shown to have a significant impact on well-being, satisfaction and comfort as well as health conditions of building occupants[15],which consequently do affect work performance, absenteeism, presenteeism, staff turnover and tenant loyalty[16] .

These effects are seldom or nearly never quantified during energy renovation of buildings although energy renovation can in many cases result in improved IEQ. EPBD[17] requires that energy renovation projects should not reduce IEQ, and as shown by the recent report of JRC[18] this may be the case. It is expected that quantification of benefits associated with energy renovation that result in improved IEQ will outweigh the renovation costs thereby bringing an additional and strong incentive to initiate and perform energy renovation. The main reason is their magnitude compared to expenditures resulting in a quick return on investments.

Following this line of reasoning and acknowledging the existence of data allowing economic valuation of improved IEQ, one of the objectives of ALDREN is defining an IEQ rating and the integration of benefits resulting from higher IEQ in the financial valuation of the deep energy renovation projects.

To achieve this goal, ALDREN worked out the list of parameters describing IEQ. These parameters are linked with the occupants' well-being, comfort and health as well as with work performance and sleep quality (sleep quality is considered as the scope of ALDREN includes both hotels and office buildings). 
This is done to allow economic valuation. These parameters are also linked with the actions taken during energy renovation that modify them. This is done because ALDREN does not define actions that are specifically directed to improve IEQ. ALDREN merely monitors and quantifies how energy renovation actions impact IEQ.

The process of selection of parameters defining IEQ, their measurement and classification of buildings based on their levels are described briefly hereafter.

The selection of parameters defining IEQ was a two-stage process.

- $\quad$ First parameters that can be modified by energy renovation were identified together with parameters for which (known) quantitative relationships exist between their levels, work performance, and sleep quality.

- Secondly, the list with IEQ parameters was supplemented by other parameters that are also used to describe IEQ.

To guide this process, national building codes, national and international standards[19], as well as certification schemes (e.g. Level(s), HQE, IVE, Itaca, BREEAM, DGNB, LEED, CASBEE) were reviewed to identify which IEQ parameters are addressed in these documents and which levels are recommended[20]. In this way, the compatibility of ALDREN approach was ensured.

The following parameters describing IEQ were selected to describe:

- thermal environment: $\%$ time outside thermal comfort;

- indoor air quality: ventilation rate, $\mathrm{CO}_{2}, \%$ humidity, mould, formaldehyde, benzene, $\mathrm{PM} 2.5, \mathrm{NO}_{2}$, radon and the use of low-emission materials;

- acoustic environment: noise level, and reverberation time;

- visual environment: glare, light colour, and illuminance;

- ability to control IEQ: control of temperature, air quality, daylight, artificial light, the presence of operable windows, thermostats, blinds.

It is acknowledged that this list is not complete as many more parameters are used to describe IEQ. But the selection had to be pragmatic especially considering that the quantification of these IEQ parameters is only supporting the energy renovation process proposed by ALDREN: it should not significantly increase expenditures or complicate the energy renovation. The list seems to be sufficient to perform a decent economic valuation of the benefits related to improved IEQ and a satisfactory classification of IEQ conditions before and after renovation.

Detailed protocols are developed allowing quantification of IEQ parameters. It is proposed that IEQ parameters are quantified by simulations, measurements, and observations all performed before energy renovation and after renovation. In the case of the former, the energy simulation software is used to model and predict some IEQ parameters that are the output parameters from these models by default. The simulation results can be verified by measurements especially in locations and during periods identified by the models to be critical thereby the modelling providing an important guidance. These parameters that cannot be simulated are quantified by measurements, and these that cannot be measured (e.g., the presence of operable windows or thermostats) by observation.

The results of simulations, measurements and observations are used not only to perform economic calculations but also to classify IEQ in a building before and after renovation. It is proposed that classification follows the IEQ categories proposed by the standard EN 16798 [18] and is supplemented by the information on the compliance with health requirements defined by WHO Air Quality Guidelines[21, 22]. The classification is compatible with classes used by the EVC supported by ALDREN.

\section{LINKING EVCS TO FINANCIAL VALUATION (T2.5)}

Financial valuation in the ALDREN project will set a framework to establish explicitly the link between the certified energy performance, wellbeing and IEQ and financial and economic indicators. It will define how, beyond the expected energy savings, well-being and IEQ can be "translated" into financial value.

Main existing approaches of the links between energy performance of buildings, well-being and IEQ and economic and financial value of real estate assets have been analysed.

In particular, a focus has been made on:

- the different types of economic and financial values and the different types of valuation and appraisal situations;

- the different types of approaches to assess the financial and/or economic performance of energy efficient buildings, well-being and IEQ.

The main issues to increase the success of the link between energy renovation and financial valuation are:

- The need to address Financial Market players with their own language;

- Ensure that the methodology proposed can be easily integrated into current practices.

Environmental, health and well-being indicators have already been defined in the other ALDREN tasks (see before).

The translation into financial value will be approached through several financial indicators. The key focus could be property value for the investment community and the credit risk for the finance provider. The exact methods to address links between energy performance, well-being 
and IEQ and those indicators represent the core task of ALDREN financial valuation.

Based on the state of the art and completed by interviews and workshops with representatives of market players, the ALDREN approach will be defined.

ALDREN Alliance members acting as finance providers will be closely involved in the developments in order to ensure maximum market uptake.

After having chosen the methodology and the detailed indicators the methodology will be tested on the pilots selected for the ALDREN project.

The financial valuation is the final stage in the interaction of the ALDREN outcomes and dependent on the outcomes of the other ALDREN tasks.

\section{BUILDING RENOVATION PASSPORT (T2.6)}

The introduction of the Building Passport (BP) aims to provide building information to the property owners, to the building stock managers who must deal with investment and renovation issues and to potential purchasers, investors, renters or building users. An important premise of the BP is that the quality assurance system for buildings relies heavily on documentation processes that are often not sufficiently robust to support this reliance.

The term Building Passport is currently being used with different meanings and there is no single definition. It can denote:

- a certificate, displaying the most important performance characteristics and technological data of a building - comparable with motor vehicle documents - as well as;

- a comprehensive collection of various buildingrelated documents (plans, calculations, lists of materials and products used, operating and maintenance guidelines, etc.).

Building passports have evolved over time and continue to evolve into a tool for communicating diverse buildings features to multiple beneficiaries in different European countries[23].

One of the most often quoted barriers of building renovation is the lack of knowledge about what to do, where to start, and which measures to implement in which order.

In this framework, the EU directive 2018/844[24] underlines the need for Member States to prepare and implement national Long-Term Renovation Strategies (LTRS) for their building stock and introduces the possibility for Member States (MS) to introduce an optional scheme for individual building renovation passport (BRP (Article 2a.1(c)). Within the state of the art on available knowledge on voluntary certification schemes and EPCs for Non-residential buildings, ALDREN project clearly demonstrated a lack of data and connections between those instruments with the Building
Renovation Passport (BRP). Similarly, it has been stated within iBroad project[25] for Residential buildings.

According to the first lessons learned from the BRP for residential buildings in French, Germany, Belgium and Denmark[26] and the review on the first experiences of EVCS, the ALDREN approach has been developed under the following important key points to follow for the BRP definition:

- ALDREN BRP should provide more detailed renovation strategy including the lifespan of components and sequence of technical steps towards deep Renovation;

- ALDREN BRP must serve to different people, from technical staff and designers to building owners, to ease the decision-making process. If a detailed roadmap passport is available, short extract could be included in the EPC recommendations. There is a need to formulate which kind of correlation there will be between existing voluntary certification schemes, EPC and BRP.

The project consortium has developed the first draft template of the Data Model for the final structure of the ALDREN BRP, considering all the inputs and parameters of the topics presented in the previous sections of the present paper.

The main characteristic agreed for the ALDREN BRP is the modular structure composed basically by two main elements:

1. ALDREN logbook

2. ALDREN roadmap.

Each element is sub-structured in modules per different issues corresponding to the topics investigated within the ALDREN approach of the whole project.

The ALDREN Logbook will be structured in 6 modules:

- ML1 Building picture

- ML2 Energy rating assessment

- ML3 Operational energy performance

- ML4 Comfort and wellbeing

- ML5 Cost, value and risk

- ML6 Documentation and BIM

While the ALDREN Roadmap will be structured in 3 modules:

- MR1 ALDREN Renovation time-line

- MR2 Elementary renovation action list

- MR3 Elementary renovation action description

Each module of the ALDREN logbook has a specific data model with dedicated database (DB) and indicators (some they might be in common with other modules).

The DB of each module will be structured into four granularity levels (from Level 0 to Level (3). Only the data of Level 2 and 3 will appear on the ALDREN 
Logbook. The other two previous data levels will be stored and available being part of the ALDREN approach.
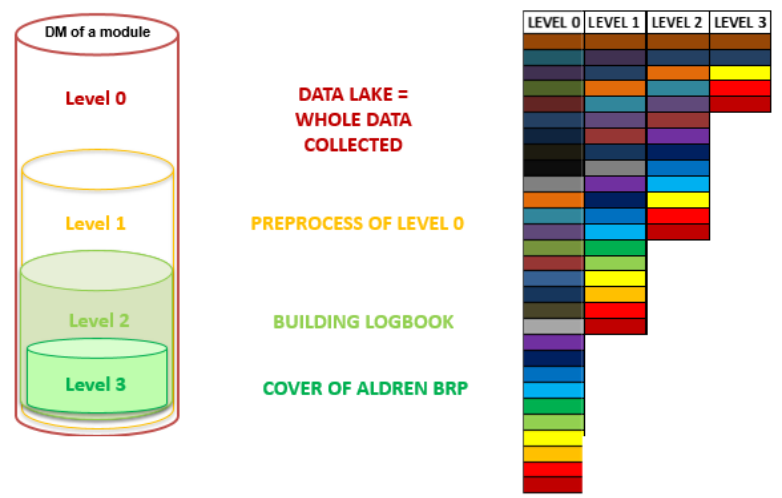

Fig. 5. Schematization of an ALDREN module DM structure

- Level 0 comprehends the whole amount of data collected for each topic,

- Level 1 is the results of a preprocess on the data of the level 0 according to the ALDREN approach

- Level 2 contains the data that will appear on the Logbook

- Level 3 represents the final selection of the core data that will appears on the cover of the ALDREN BRP.

The structure into levels for each DB is derived from the need to collect all the necessary data which qualifies the current building condition and calculate, estimate the future needs or consumptions. Different level of data granularity will facilitate the data comprehension for different target groups according to their knowledge/expertise.

\section{THE ALDREN ROLL-OUT}

In this article it has been analyzed how ALDREN goes beyond saving energy. ALDREN is a strategy to mobilize the construction industry by evaluating the financing viability and by highlighting collateral benefits to energy building renovation, as improving health and wellbeing. ALDREN goes beyond EVCS (energy) and incorporates health and well-being, verified performance and financial valuation, because often the energy savings alone do not motivate the building owners in non-residential sector to trigger deep renovation.

However, Voluntary Building Certification Schemes have been around for some years now in Europe and worldwide. ALDREN accounts with the support of Sustainable Building Alliance (SBA), a worldwide organization that reunited at the Board level the main voluntary building certification schemes: USGBC (LEED), BRE (BREEAM), CSTB (HQE), DGNB (DGNB Certificate), FCAV (AQUA), VTT, ITC-CNR,
IVE. Sustainable Building Alliance's goal is to develop common metrics that can be used to monitor and compare internationally sustainable performance through different voluntary rating schemes. Generally, the objective for building developers to engage into a certification is to have their buildings broadly recognized. ALDREN is not starting from scratch but building on the experience of SBA by working out the common metrics. The ALDREN scheme will first be applied on pilots by existing environmental scheme providers (certification bodies like IVE, CERTIVEA).

Moreover, one of the main tools to ensure the rollout of ALDREN is the creation of a common place for this collaborative understanding. This common place has two components: an online platform[27] and a strategic alliance, the ALDREN ALLIANCE, with relevant market players and stakeholders.

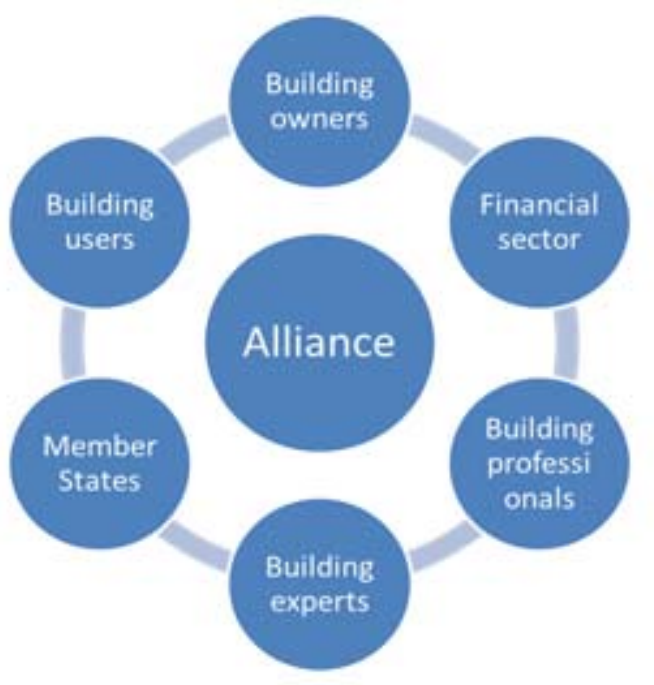

Fig. 6. The ALDREN ALLIANCE - buildings deep renovation stakeholders

Other existing powerful channels will be used for the ALDREN roll-out. ALDREN is collaborating with projects and professional organisations as e.g. ENERFUND, QUANTUM, EUROACE or RICS.

To increase the renovation rate and renovation quality in Europe the cooperation of all actors is needed. Support is key for the success of ALDREN. JOIN ALDREN! (www.aldren.eu/contact) 


\section{References}

1. BPIE. Multiannual financial framework beyond 2020: five principles to improve how the EU finances building renovation and a nearly zero energy building stock.

2. DG Ener website, visited on $04 / 09 / 2018$ https://ec.europa.eu/energy/en/topics/energyefficiency/buildings

3. Artola I, et al. Boosting Building Renovation: What potential and value for Europe? Study for the Itre Committee of the European Parlament (2016) http://www.europarl.europa.eu/RegData/etudes/STUD/2016/ 587326/IPOL STU(2016)587326 EN.pdf

4. Adrian Joyce, Secretary General, EuroACE, presentation to ALDREN partners meeting, Brussels. (10 April 2018).

5. Survey results from: https://www.energyagency.at/fileadmin/dam/pdf/veranstaltun gen/TABULA/01_Oliver_Rapf.pdf

6. "Technical assessment of national/regional calculation methodologies for the energy performance of buildings ", Final report (2015-01-30)

https://ec.europa.eu/energy/sites/ener/files/documents/EPB c alculations in EU.pdf

7. Bendzalova J., "Specific criteria related to the label (display) and the content of energy performance certificate", Workshop - public consultation, Tender No. ENER/C3/2015545 "Enabling the European Common Voluntary Certification Scheme for non-residential buildings" Paris, (April 2016)

8. Cohen RR and Waring G, "A methodology to address the gap between calculated and actual energy performance in deep renovations of offices and hotels", IEECB'18, Frankfurt, (March 2018).

9. Cohen, RR, Austin, BS, Bannister, P, Bordass, WT and Bunn, R, "How the commitment to disclose in-use performance can transform energy outcomes for new buildings", BSER\&T Special Issue, (2017). http://journals.sagepub.com/doi/full/10.1177/0143624417711 $\underline{343}$

10. World Green Building Council Health, Wellbeing and Productivity in Offices: The Next Chapter for Green Building. (2014)

11. Wargocki, P., \& Djukanovic, R. (2005). Simulations of the Potential Revenue from Investment in Improved Indoor Air Quality in an Office Building. ASHRAE transactions, 111(2).

12. Woods, J. E. Cost avoidance and productivity in owning and operating buildings. Occupational medicine (Philadelphia, Pa.), 4(4), 753-770. (1989).

13. Wargocki, P., \& Seppänen O. Rehva Guidebook No. 6: Indoor climate and productivity in offices-How to integrate productivity in life-cycle cost analysis of building services. ed. Rehva:(Finland). (2006).
14. Wargocki, P., \& Wyon, D. P. Ten questions concerning thermal and indoor air quality effects on the performance of office work and schoolwork. Building and Environment, 112, 359-366. (2017)

15. Spengler, J. D., Samet, J. M., \& McCarthy, J. F. Indoor air quality handbook. (2001)

16. Buildings 2030. Building 4 people: People-centric buildings for European citizens. (2018)

17. EPBD. Directive 2010/31/EU of the European Parliament and of the Council of 19 May 2010 on the energy performance of buildings (recast). Official Journal of the European Union, 18(06), 2010.

18. JRC. Promoting healthy and highly energy performing buildings in the European Union. National implementation of related requirements of the Energy Performance Buildings Directive (2010/31/EU). Joint Research Centre Science for Policy Report. (2017)

19. EN 16798-1 (2018) Energy performance of buildings Ventilation of buildings - Part 1: Indoor environmental input parameters for design and assessment of energy performance of buildings addressing indoor air quality, thermal environment, lighting and acoustics. CEN (under approval)

20. Wei, W., Wargocki, P. and Mandin, C. (in preparation). A review of indoor environmental quality metrics. (2019)

21. WHO, World Health Organization: Air quality guidelines for Europe. (2000)

22. WHO, World Health Organization: Guidelines for indoor air quality: selected pollutants. (2010).

23. Sesana M. M., Salvalai G. A review on Building Renovation Passport: Potentialities and barriers on current initiatives. Energy \& Buildings 173 195-205, (2018)

24. Directive (EU) 2018/844 of the European Parliament and of the Council of 30 May 2018 amending Directive 2010/31/EU on the energy performance of buildings and Directive 2012/27/EU on energy efficiency, available at: https://eur-lex.europa.eu/legalcontent/EN/TXT/?uri=uriserv\%3AOJ.L 2018.156.01.0075.01.ENG

25. Individual Building (Renovation) Roadmaps, iBROAD, Project ID: 754045, from 2017 to 2020, website: https://ibroad-project.eu/

26. M. Fabbri, Understanding building renovation passports: customized solutions to boost deep renovation and increase comfort in a decarbonized Europe, ECEE 2017 summer study consumption, efficiency \& limits 29 May-3 June 2017 Belambra Les Criques, Toulon/Hyères, France. available at: https://www.eceee.org/static/media/uploads/.../summerstud y/eceee2017abstractsbook.pdf

27. http://aldren.eu/ 